\title{
An Automatic Titration System for Oil Concentration Measurement in Metalworking Fluids
}

\author{
M. Grossi*, B. Riccò
}

* Corresponding author : marco.grossi8@unibo.it, Tel. 0039-0512093078, Fax 0039-0512093785

Department of Electrical Energy and Information Engineering "Guglielmo Marconi" (DEI), University of Bologna, Bologna, Italy

\begin{abstract}
Most Metalworking Fluids (MWFs), widely used for cooling and lubrication, consist of oils diluted in water in concentration ranging from $1 \%$ to $10 \%$. To guarantee good performance and reliability of both machines and processes, oil concentration should be maintained (approximately) constant, hence also measured at regular intervals to compensate for significant deviations from the optimal value. The official technique to measure oil concentration in MWFs is titration with $0.5 \mathrm{M} \mathrm{HCl}$ solution and endpoint detection obtained measuring the sample $\mathrm{pH}$. Such a method is accurate and substantially insensitive to sample contamination, but must be carried out in a laboratory, while fast, inexpensive and in-situ measurements would be desirable for effective process and machine control. This paper presents a system to measure oil concentration in MWFs that is new in that: a) titration is made automatic using a stepper motor; b) the end-point is detected by means of electrical conductance measurements. Experimental results show a very good correlation $\left(\mathrm{R}^{2}=0.9793\right)$ between the oil concentrations of prepared solutions and those measured with the proposed technique, while the presented system is suitable for in-situ operation within working environment.
\end{abstract}

Keywords: embedded systems, metalworking fluids, impedance spectroscopy, electrical conductance, titration, oil concentration.

\section{Introduction}


Metalworking Fluids (MWFs), widely used in metal cutting industries for cooling and lubrication [1], are soluble oils diluted in water in concentrations ranging from $1 \%$ to $10 \%$, with the addition of special additives (anti-microbial compounds to prevent bacterial degradation [2][3], corrosion inhibitors, emulsifiers, pressure additives and anti-foam agents).

During the product lifetime the oil concentration $\left(\mathrm{C}_{\mathrm{oil}}\right)$ tends to vary due to various reasons such as, in particular: water evaporation, bacterial attack to the oil compounds and oil adhesion to metal parts. Instead, in order to achieve good performance and prevent potential malfunctions and reliability problems, $\mathrm{C}_{\mathrm{oil}}$ should be kept at its optimal value (depending on water characteristics, material to be worked, type of machine,...), since if it is too low poor lubrication, corrosion of both machine tools and metal parts and insufficient anti-microbial effect can occur, while if $\mathrm{C}_{\mathrm{oil}}$ is too high problems can arise concerning formation of foam, possible tool malfunction due to excessive lubricity and potential health problems for the exposed workers [4][5][6].

Thus, $\mathrm{C}_{\mathrm{oil}}$ in MWFs should be measured at regular intervals and significant deviations from the optimal value should be compensated for.

The official technique to measure $C_{o i l}$ in MWF samples is potentiometric titration [7], where a sample of the fluid under test $(100 \mathrm{ml})$ is titrated with a $0.5 \mathrm{M} \mathrm{HCl}$ solution to an end-point of $\mathrm{pH}=4$ and the volume of titrant $(0.5 \mathrm{M} \mathrm{HCl})$ required to reach the end-point is used to calculate $\mathrm{C}_{\mathrm{oil}}$. This technique, estimating the oil concentration through the sample alkalinity, is accurate and not significantly affected by fluid contamination [8][9], but must be carried out by qualified personnel in a Lab. Thus, it is unsuitable for "in-situ" measurements inside metal working plants.

For this reason, potentiometric titration is replaced as industrial standard by measurement of the sample refractive index [10], a technique not requiring expensive instruments (an analog refractometer costs about 200 to $250 \$$ ) and suitable for quick, "in-situ" measurements. However, to achieve good accuracy the instrument must be frequently calibrated. Furthermore, refractometry is affected by the contamination of the sample (old and contaminated MWF samples are characterized by lower accuracy in the measured concentration) [8]. Recently, portable digital refractometers 
(with a cost of 300 to $400 \$$ ) have been introduced into the market, that solve some of the problems of analog refractometers, but accuracy deterioration with fluid contamination remains a critical issue.

Other techniques to measure the oil concentration in MWFs have been proposed, that are based on the measurement of viscosity [11], density [12] and ultrasound speed [13]. This work, instead, deals with the standard titration technique with the aim to make it automatic, thus usable for in-situ measurements in working environment.

The possibility of quick but accurate "in-situ" measurements is highly desirable in a wide range of applications and substantial efforts have been done to find viable solutions. Some examples of this kind of work are: a portable station for weather monitoring [14]; a system for automatic detection and classification of telecommunication signals [15]; a multi-sensor data logger for medical surveillance in harsh environment [16]; a benchtop electronic system to characterize ice cream mixes [17] and control the freezing point of ice-cream [18]; a gas chromatography for analysis of combustible gases in the coal mining industry [19]; an electronic system to measure the free acidity [20][21] as well as peroxide value and total phenol content [22] in olive oil.

In this paper, a benchtop set-up has been developed to measure $\mathrm{C}_{\mathrm{oil}}$ in MWF samples by means of titration that improves the state of the art in the field in two critical aspects: 1) the end-point is determined by measuring the sample electrical conductance, instead of its $\mathrm{pH}$; 2) the whole operation is made automatic. The experimental results obtained with such a system show a very good correlation with the technique based on manual potentiometric titration $\left(\mathrm{R}^{2}=0.9793\right)$.

The developed (electro-mechanical) system, based on the Arduino Uno development board [23], includes: a) a $5 \mathrm{ml}$ syringe containing the titrant solution $(0.5 \mathrm{M} \mathrm{HCl})$; b) a $50 \mathrm{ml}$ vial, to be filled with the Sample Under Test (SUT), (15ml of MWF) and featuring a couple of stainless steel electrodes allowing electrical measurements. 
To allow titrant drops to fall into the SUT, the syringe plunger is pushed using a $1.33 \mathrm{~A}\left(1.8^{\circ}\right.$ step angle) stepper motor controlled by the system microcontroller, while the SUT electrical conductivity is measured to detect the titration end-point.

Tests carried out on a number of MWF samples have shown that this system can measure $\mathrm{C}_{\text {oil }}$ with an accuracy comparable to that obtained with manual titration, with the important advantage that the system is automatic and suitable for in-situ measurements within metal working environment. Furthermore, the bench-top system of this work is suitable to be realized in the form of a single compact instrument.

\section{Materials and methods}

First, the experimental set-up shown in Fig. 1 (a) has been used to test the feasibility of oil concentration measurement using the conductivity-based titration of interest for this work. A 50ml polypropylene vial featuring a couple of cap-shaped stainless steel electrodes is used to host the SUT and its characterization during the titration procedure by means of Electrical Impedance Spectroscopy (EIS), a powerful technique used in different applications, such as bacterial concentration measurements in different types of samples [24][25][26][27][28][29][30][31]; analysis of human body composition [32][33][34][35]; quality analysis of food products [36][37][38][39]; corrosion monitoring of metallic surfaces in contact with acid electrolytes $[40][41][42][43]$.

EIS consists in the application of a sine-wave test voltage to the SUT with measurement of the induced current to calculate the SUT complex impedance in a wide range of frequencies. In our case, EIS measurements have been carried out using an Agilent E4980A LCR meter (with a sinewave amplitude of $100 \mathrm{mV}$ and frequency range from $20 \mathrm{~Hz}$ to $2 \mathrm{MHz}$ ). The electrical parameters $(\operatorname{Re}(\mathrm{Y})$ and $\operatorname{Im}(\mathrm{Y}))$ acquired by the LCR meter are transferred to a PC lap-top for data processing and filing. All the software to control the instrumentation and transfer data has been written using LabVIEW (National Instruments, USA). 
The titrant solution $(0.5 \mathrm{M} \mathrm{HCl})$ is manually added to the SUT using a micropipette in steps of 160 $\mu \mathrm{L}$ each: after each step the vial is gently stirred and a measurement of the electrical parameters is carried out.

The system composed of the SUT and the electrodes can be modelled with the circuit of Fig. 1 (b). With such a model, the admittance $\mathrm{Y}$ of the electrodes-electrolyte system can be written as:

$$
Y=\frac{1}{Z}=\left(\frac{1}{G_{m}}+Z_{Q}\right)^{-1}=\left(\frac{1}{G_{m}}+\frac{1}{Q(j \omega)^{\alpha}}\right)^{-1}=\left(\frac{1}{G_{m}}+\frac{\cos \left(\frac{\alpha \pi}{2}\right)}{Q \omega^{\alpha}}-j \frac{\sin \left(\frac{\alpha \pi}{2}\right)}{Q \omega^{\alpha}}\right)^{-1},
$$

where $G_{m}$ is the bulk electrical conductance of the sample and $Z_{Q}$ is a constant phase element accounting for the non-linear capacitive behaviour of the electrode-sample interface [44] (Q represents the double layer capacitance while $\alpha$ accounts for the non ideal electrode-medium interface).

When not otherwise specified, measurements have been carried out on MWF samples prepared using the product "Spirit MS 8200" by Total.

Fig. 1 (c) shows the Nyquist diagram $(\operatorname{Im}(Y)$ vs. $\operatorname{Re}(Y))$ for the tested frequency range, in the case of a MWF sample with $\mathrm{C}_{\mathrm{oil}}=4.46 \%$. If the test frequency is sufficiently high, the corresponding diagram is a semicircle with its centre below the $\mathrm{x}$-axis (i.e. $\operatorname{Re}(\mathrm{Y})>0, \operatorname{Im}(\mathrm{Y})<0$ ) and $\mathrm{G}_{\mathrm{m}} \approx$ $\operatorname{Re}(Y)$. The experimental data of Fig. 1 (c) have been fitted with the model of Eq. 1 using the software Multiple Electrochemical Impedance Spectra Parametrization (MEISP) v3.0 , by Kumho Chemical Laboratories and the results show a very good correlation $\left(\mathrm{R}^{2}=0.9876\right)$.

Fig. 2 (a) and (b) show the Bode plots $(\operatorname{Re}(Y)$ and $\operatorname{Im}(Y)$ vs. frequency) for a MWF sample with $\mathrm{C}_{\mathrm{oil}}=4.46 \%$ after the addition of different volumes of the titrant solution. As can be seen, initially the variations of the electrical parameters are moderate (since the oil alkaline compounds neutralize the $\mathrm{HCl}$ ), but after a critical injection of titrant (depending on $\mathrm{C}_{\mathrm{oil}}$ ), further increases of titrant result in much stronger variations. 
Since the electrical conductivity depends on the temperature, samples have been characterized by storing the SUT in a thermal incubator Binder APT KB 53 and measuring the electrical parametrs at three different temperatures: $15^{\circ} \mathrm{C}, 25^{\circ} \mathrm{C}$ and $35^{\circ} \mathrm{C}$.

Figs. 2 (c) and 2 (d) show the Bode plots for a MWF sample with $\mathrm{C}_{\mathrm{oil}}=6 \%$ for the three tested temperatures. Even if both $\operatorname{Re}(Z)$ and $\operatorname{Im}(Z)$ increases with temperature, the end-point of a conductometric titration is not affected by temperature [45][46], since the critical volume of added titrant is determined by changes and not absolute values of the measured electrical conductance. The only constraint of the measurement is that temperature is stable during a single experiment, to separate conductivity changes due to titrant addition from those due to temperature variations. More precisely, results of Section 3 indicate that a maximum temperature variation of $3^{\circ} \mathrm{C}$ can be tolerated during a single experiment.

Therefore, all presented measurements hereafter have been carried out at room temperature $\left(23^{\circ} \mathrm{C}\right)$. In search of a satisfactory trade-off between accuracy and measurement simplicity, three different electrical parameters have been investigated, namely: a) the real component of the admittance $\operatorname{Re}(\mathrm{Y})$ measured at $300 \mathrm{kHz}$, that represents a good estimate of the bulk electrical conductance $\mathrm{G}_{\mathrm{m}}$; b) the maximum value of $\operatorname{Im}(\mathrm{Z})$; c) the frequency at which such a maximum value is obtained (resonance frequency).

The experimental results indicate that the value of $\operatorname{Re}(\mathrm{Y})$ at $300 \mathrm{kHz}$ and the maximum value of $\operatorname{Im}(\mathrm{Y})$ provide comparable accuracy in the determination of $\mathrm{C}_{\mathrm{oil}}\left(\mathrm{R}^{2}=0.9793\right)$, while the resonance frequency of $\operatorname{Im}(\mathrm{Y})$ results in lower accuracy $\left(\mathrm{R}^{2}=0.9305\right)$. Since $\mathrm{Re}(\mathrm{Y})$ at $300 \mathrm{kHz}$ is a single frequency measurement while the determination of the maximum value of $\operatorname{Im}(\mathrm{Y})$ requires a multifrequency approach, $\operatorname{Re}(\mathrm{Y})$ at $300 \mathrm{kHz}$ (hereafter simply used for the bulk conductance $\mathrm{G}_{\mathrm{m}}$ ) has been chosen as the most convenient "detection parameter", to be used hereafter.

\section{Results and discussion}


A set of MWF samples (both new and much used) featuring different values of $\mathrm{C}_{\mathrm{oil}}$ have been tested with the experimental set-up described in Section 2. Fig. 3 (a) shows the electrical conductance variation $G_{m}-G_{m 0}$ (where $G_{m 0}$ is the value of $G_{m}$ before any titrant inoculation, i.e. at time 0 ) as a function of the volume of added titrant for four different samples featuring $\mathrm{C}_{\mathrm{oil}}=2.91 \%, 4.46 \%$, $7.12 \%$ and $10.45 \%$, respectively. As mentioned in Section 2, the initial addition of titrant is neutralized by the oil alkaline compounds and $\mathrm{G}_{\mathrm{m}}$ increases moderately. However, after a critical volume of the added titrant the alkaline compounds are entirely neutralized and this leads to a strong increase in $\mathrm{G}_{\mathrm{m}}$. As can be seen, the critical volume of titrant increases with $\mathrm{C}_{\mathrm{oil}}$.

Fig. 3 (b) shows the critical volume of titrant plotted vs $\mathrm{C}_{\text {oil }}$ for all the tested MWF samples. A very good linear correlation is found between the two variables $\left(\mathrm{R}^{2}=0.9793\right)$, while the achieved calibration line is $\mathrm{Y}=124.37 \cdot \mathrm{X}+155.83$ and the technique sensitivity (expressed as variation in the critical volume of titrant for differences of $1 \%$ in oil concentration) is $124.37 \mu \mathrm{L}$. The achieved calibration line features a good linearity: the calculated non linearity (expressed as the ratio between maximum deviation of data from the linear regression line and full scale of $\mathrm{C}_{\mathrm{oil}}$ ) is $7.32 \%$.

Using the calibration line, $\mathrm{C}_{\mathrm{oil}}$ can be estimated with good accuracy from the critical volume of titrant, determined by the intersection of the two lines used for a piecewise linear fit of the experimental data [47].

Since the calibration line is characteristic of any the particular MWF, to achieve good measurement accuracy a calibration line must be calculated for any new product. As an example, the Supplementary Material shows the calibration lines for samples prepared with different oil products.

In Fig. 3 (c) the estimated $\mathrm{C}_{\text {oil }}$ is plotted vs the real value of $\mathrm{C}_{\mathrm{oil}}$ for all tested samples. The corresponding linear regression line features a slope very close to one $\left(1+38.8 \cdot 10^{-6}\right)$ and an offset of $7.26 \cdot 10^{-6}$ : thus the precision of the estimated $C_{\text {oil }}$ is high (the average error is $207.4 \cdot 10^{-6}$ ). The accuracy of the estimated $\mathrm{C}_{\mathrm{oil}}$ is also good, with a standard deviation of the differences between estimated and real $\mathrm{C}_{\mathrm{oil}}$ of 0.4988 . 
To test the repeatability of the titration assay, four different samples have been tested in duplicate: three were fresh with $\mathrm{C}_{\text {oil }}=4.46 \%, 7.12 \%, 10.45 \%$, respectively while the fourth was a contaminated sample with $C_{o i l}=0.75 \%$. Fig. 3 (d) shows $G_{m}-G_{m 0}$ vs. the volume of added titrant in the case of a fresh sample with $\mathrm{C}_{\mathrm{oil}}=7.12 \%$ for two different assay replicas. The variation in the critical volume of titrant for replicated assays is, for all the tested samples, not higher than 25.75 $\mu \mathrm{L}$, corresponding to a variation in estimated $\mathrm{C}_{\mathrm{oil}}<0.21 \%$.

Measurements have been also carried out to test the effects of sample contamination on measurement accuracy. To this purpose, a sample has been tested: a) before any contamination; b) after adding a moderate amounts of contaminants; c) after adding an high amount of contaminants. The results, presented in the Supplementary Material, show that the presence of contaminants produce only a very small increase in the estimated oil concentration (variation $<0.227 \%$ ), thus proving that the proposed technique is essentially insensitive to fluid contamination.

As for the mechanics of titration, the procedure has been made automatic by means of the system shown in Fig. 4, based on the Arduino UNO development board and composed of two electronic boards designed "ad hoc" in order to: 1) measure the sample $\mathrm{G}_{\mathrm{m}}$; 2) control the $1.8^{\circ}$ stepper motor pushing the syringe plunger [48].

The system works as follows. First, the sensor vial is filled with $15 \mathrm{ml}$ of the SUT while the syringe is charged with $5 \mathrm{ml}$ of the titrant solution $(0.5 \mathrm{M} \mathrm{HCl})$. Then a cycle of the following steps starts. Every $250 \mathrm{~ms}$ the Arduino board acquires the $\mathrm{G}_{\mathrm{m}}$ value from the measurement board (to detect the drop of titrant solution) and enables the stepper motor to push the syringe plunger. When a drop of titrant solution is inoculated into the sample, the Arduino board disables the stepper driver, waits 12 seconds, then measures $G_{m}$ (after titrant drop inoculation) and sends the value to the lap-top via serial interface. The stepper motor is then enabled again and a new cycle starts until the user presses a stop button on the software user interface.

Details on the microcontroller firmware and LabVIEW program to transmit/receive and analyse data are provided in the Supplementary Material. 
The circuit used to measure $G_{m}$ is described in Fig. 4 (b). A XR-2206CP monolithic fuction generator provides the sine wave voltage $\mathrm{V}_{\mathrm{A}}(\mathrm{t})=\mathrm{V}_{\mathrm{MA}} \cdot \sin (2 \pi \mathrm{f} t)\left(\mathrm{V}_{\mathrm{MA}}=1 \mathrm{~V}, \mathrm{f}=300 \mathrm{kHz}\right)$. Using a voltage divider and a voltage follower the sine wave signal $V_{\text {in }}(t)=V_{M i n} \cdot \sin (2 \pi f t)\left(V_{\text {Min }}=100 m V\right.$ and $\mathrm{f}=300 \mathrm{kHz}$ ) is then generated. This signal is applied to the vial electrodes and, by means of an I-V converter, a voltage $\mathrm{V}_{\mathrm{X}}$ (proportional to the current through the electrodes) is generated, that can be written as:

$V_{X}(t)=-R_{F} \cdot|Y| \cdot V_{M i n} \cdot \sin (\omega t+\varphi)$

where $\varphi$ is the phase of the measured admittance $Y$. The voltage $V_{X}$ is further amplified by a factor $\mathrm{K}_{1}=-\mathrm{R}_{2} / \mathrm{R}_{1}$ to produce the signal $\mathrm{V}_{\mathrm{B}}$ :

$V_{B}(t)=-\frac{R_{2}}{R_{1}} \cdot V_{X}(t)=\left|K_{1}\right| \cdot R_{F} \cdot|Y| \cdot V_{M i n} \cdot \sin (\omega t+\varphi)$

The two sine-wave signals $\mathrm{V}_{\mathrm{A}}$ and $\mathrm{V}_{\mathrm{B}}$ are fed to an AD633 analog multiplier to produce the signal:

$$
V_{Y}(t)=\frac{V_{A}(t) \cdot V_{B}(t)}{10}=\frac{V_{M A} \cdot V_{M i n} \cdot\left|K_{1}\right| \cdot R_{F}}{10} \cdot|Y| \cdot \sin (\omega t) \cdot \sin (\omega t+\varphi)
$$

Denoting $\mathrm{K}_{2}=\left(\mathrm{V}_{\mathrm{MA}} \cdot \mathrm{V}_{\mathrm{Min}}\left|\mathrm{K}_{1}\right| \cdot \mathrm{R}_{\mathrm{F}}\right) / 10$, it is:

$V_{Y}(t)=K_{2} \cdot|Y| \cdot \sin (\omega t) \cdot \sin (\omega t+\varphi)=K_{2} \cdot|Y| \cdot \frac{1}{2} \cdot[\cos (\varphi)-\cos (2 \omega t+\varphi)]$

$\mathrm{V}_{\mathrm{Y}}$ is the sum of two terms: a DC and a sinewave component of frequency $600 \mathrm{kHz}$. By means of a low-pass filter with cut-off frequency of $1942 \mathrm{~Hz}$, the signal $\mathrm{V}_{\mathrm{Z}}$ is generated that is proportional to $|\mathrm{Y}| \cdot \cos (\varphi)=\mathrm{G}_{\mathrm{m}}$. Thus:

$V_{Z}(t)=\frac{1}{2} \cdot K_{2} \cdot|Y| \cdot \cos (\varphi)=\frac{1}{2} \cdot K_{2} \cdot G_{m}$

Further amplification and filtering generates a signal $V_{\text {out }}$ (proportional to $G_{m}$ ) that is acquired by one of the Arduino UNO analog input channels and used to calculate $\mathrm{G}_{\mathrm{m}}$.

Figs. 5 (a) and (b) show how the inoculation of a titrant drop into sample is recognized. The system measures $G_{m}$ every $250 \mathrm{~ms}$ and a steep increase in $\mathrm{G}_{\mathrm{m}}$ is detected at any new titrant drop. At every step $\Delta \mathrm{G}_{\mathrm{m}}$ is calculated and when $\Delta \mathrm{G}_{\mathrm{m}}>0.05 \mathrm{mS}$ (Fig. 5 (b)) it is considered that a new drop of 
titrant has been added to the SUT. Then, after 12 seconds, required for a uniform distribution of the titrant within the sample, a new value of $\mathrm{G}_{\mathrm{m}}$ is measured and transmitted to the lap-top.

In Fig. 6 (a) $\mathrm{G}_{\mathrm{m}}-\mathrm{G}_{\mathrm{m} 0}$ measured after each titrant drop addition is plotted vs. the number of titrant drops for three MWF samples featuring $\mathrm{C}_{\mathrm{oil}}=1 \%, 2 \%$ and $3 \%$, respectively. The critical number of titrant drops (i.e. that needed to completely neutralize the sample alkaline compounds) is calculated for each sample using the same algorithm as in the case of the benchtop experimental setup [47] and Fig. 6 (b) shows that this value correlates very well with the sample $\mathrm{C}_{\text {oil }}$.

\section{Conclusions}

Metalworking Fluids (MWF), used in cutting industries for lubrication and cooling, need to maintain optimal oil concentration in spite of phenomena (such as water evaporation, bacterial attacks, oil adhesion to metal parts) capable of producing significant deviations. This requires that the oil concentration is periodically measured, an operation usually performed in Labs by means of manual potentiometric titration using $0.5 \mathrm{M} \mathrm{HCl}$.

Instead, oil concentration should be ideally monitored automatically within the working environment and this paper presents a solution to achieve such a goal that is based on two novel elements, namely: electrical conductance measurement instead of $\mathrm{pH}$ detection; automation of the titration operation.

Such a solution has been implemented as bench-top prototype and an excellent correlation is found with the data obtained with the standard technique $\left(\mathrm{R}^{2}=0.9793\right)$.

An automated prototype of the titration system has been built that represent the basis for an actual instrument suitable for "in-situ" measurements of MWF oil concentration within industrial plants. As a future development. a complete stand-alone microcontroller based electronic system will be designed with wireless communication to a remote host (via Bluetooth or Wi-Fi protocol). 


\section{References}

[1] D.A. Stephenson, J.S. Agapiou, Metal Cutting Theory and Practice, second ed., CRC Press, 2005.

[2] M. Cyprowski, M. Piotrowska, Z. Zakowska, I. Szadkowska-Stanczyk, Microbial and Endotoxin Contamination of Water-Soluble Metalworking Fluids, International Journal of Occupational Medicine and Environmental Health, 20, 4, (2007), 365-371.

[3] S. Bakalova, A. Doycheva, I. Ivanova, V. Groudeva, R. Dimkov, Bacterial Microflora of Contaminated Metalworking Fluids, Biotechnology and Biotechnological Equipment, 21, 4, (2007), 437-441.

[4] H. Cohen, E.M. White, Metalworking Fluid Mist Occupational Exposure Limits: A Discussion of Alternative Methods, Journal of Occupational and Environmental Hygiene, 3, (2006), 501-507.

[5] A.T. Simpson, M. Stear, J.A. Groves, M. Piney, S.D. Bradley, S. Stagg, B. Crook, Occupational Exposure to Metalworking Fluid Mist and Sump Fluid Contaminants, The Annals of Occupational Hygiene, 47, 1, (2003), 17-30.

[6] F.J. Passman, Metalworking Fluid Microbes - What We Need to Know to Successfully Understand Cause-and-Effect Relationship, Tribology \& Lubrication Technology, 68, 3, (2012), 213.

[7] J.P. Byers, Metalworking Fluids, second ed., CRC Press, 2006.

[8] Iowa Waste Reduction Center: Cutting Fluid Management for Small Machining Operations, A Practical Pollution Preventive Guide, $3^{\text {rd }}$ Edition, University of Northern Iowa (2003).

[9] Cutting Fluid Management, http://www.mfg.mtu.edu/cyberman/metal_fluids/mana.html

[10] N. Canter, Monitoring Metalworking Fluids, Tribology \& Lubrication Technology, 67, 3, (2011), 42-51.

[11] M. Grossi, B. Riccò, A portable electronic system for in-situ measurements of oil concentration in MetalWorking fluids. Sensors and Actuators A: Physical, 243, (2016), 7-14. 
[12] E. Navarro de Andrade, E. Skowron, V.W. Goldschmidt, E.A. Groll, Oil concentration in liquid refrigerants: in situ measurements. International Journal of Refrigeration, 22, 6, (1999), 499508.

[13] J.J. meyer, J.M. Saiz Jabardo, An ultrasonic device for measuring the oil concentration in flowing liquid refrigerant. International Journal of Refrigeration, 17, 7, (1994), 481-486.

[14] J.T. Devaraju, K.R. Suhas, H.K. Mohana, V.A. Patil, Wireless Portable Microcontroller based Weather Monitoring Station. Measurement, 76, (2005), 189-200.

[15] D.L. Carnì, L. De Vito, S. Rapuano, A portable instrument for automatic detection and classification of telecommunication signals. Measurement, 45 (2), (2012), 182-189.

[16] B. Hermans, R. Puers, A Portable Multi-Sensor Data-Logger for Medical Surveillance in Harsh Environments, Sensors and Actuators A: Physical, 123-124, (2005), 423-429.

[17] M. Grossi, M. Lanzoni, R. Lazzarini, B. Riccò, Automatic ice-cream characterization by impedance measurements for optimal machine setting. Measurement, 45, (2012), 1747-1754.

[18] M. Grossi, R. Lazzarini, M. Lanzoni, B. Riccò, A novel technique to control ice cream freezing by electrical characteristics analysis. Journal of Food Engineering, 106, (2011), 347-354.

[19] J.A. Dziuban, J. Mroz, M. Szczygielska, M. Malachowski, A. Gorecka-Drzazga, R. Walczak, W. Bula, D. Zalewski, L. Nieradko, J. Lysko, J. Koszur, P. Kowalski, Portable Gas Chromatograph with Integrated Components, Sensors and Actuators A: Physical, 115, 2-3, (2004), 318-330.

[20] M. Grossi, G. Di Lecce, T. Gallina Toschi, B. Riccò, Fast and Accurate Determination of Olive Oil Acidity by Electrochemical Impedance Spectroscopy, IEEE Sensors Journal, 14, 9, (2014), 2947-2954.

[21] M. Grossi, G. Di Lecce, T. Gallina Toschi, B. Riccò, A Novel Electrochemical Method for Olive Oil Acidity Determination, Microelectronics Journal, 45, 12, (2014), 1701-1707.

[22] M. Grossi, G. Di Lecce, M. Arru, T. Gallina Toschi, B. Riccò, An Opto-Electronic System for In-Situ Determination of Peroxide Value and Total Phenol Content in Olive Oil, Journal of Food Engineering, 146, (2015), 1-7. 
[23] A. D’Ausilio, Arduino: A low-cost multipurpose lab equipment. Behavior Research Methods, 44 (2), (2012), 305-313.

[24] M. Grossi, A. Pompei, M. Lanzoni, R. Lazzarini, D. Matteuzzi, B. Riccò, Total bacterial count in soft-frozen dairy products by impedance biosensor system. IEEE Sensors Journal, 9, 10, (2009), 1270-1276.

[25] M. Grossi, M. Lanzoni, A. Pompei, R. Lazzarini, D. Matteuzzi, B. Riccò, An embedded portable biosensor system for bacterial concentration detection. Biosensors and Bioelectronics, 26, (2010), 983-990.

[26] S. Puttaswamy, S. Sengupta, Rapid detection of bacterial proliferation in food samples using microchannel impedance measurements at multiple frequencies. Sensors and Instrumentation for Food Quality, 4 (2010) 108-118.

[27] K. Settu, C.J. Chen, J.T. Liu, C.L. Chen, J.Z. Tsai, Impedimetric method for measuring ultralow E. coli concentrations in human urine. Biosensor and Bioelectronics, 66 (2015) 244-250.

[28] M. Grossi, M. Lanzoni, A. Pompei, R. Lazzarini, D. Matteuzzi, B. Riccò, A portable biosensor system for bacterial concentration measurements in cow's raw milk. 4th IEEE International Workshop on Advances in Sensors and Interfaces, 2011, 132-136.

[29] M. Grossi, R. Lazzarini, M. Lanzoni, A. Pompei, D. Matteuzzi, B. Riccò, A portable sensor with disposable electrodes for water bacterial quality assessment. IEEE Sensors Journal 135 (2013) $1775-1781$.

[30] L. Gervais, M. Gel, B. Allain, M. Tolba, L. Brovko, M. Zourob, R. Mandeville, M. Griffiths, S. Evoy, Immobilization of biotinylated bacteriophages on biosensor surfaces, Sensors and Actuators B: Chemical, 125 (2007) 615-621.

[31] M. Grossi, M. Lanzoni, R. Lazzarini, B. Riccò, Linear non iterative sinusoidal fitting algorithm for microbial impedance biosensor. Sensors \& Transducers Journal, 137, 2, (2012), 235-244.

[32] U.G. Kyle, I. Bosaeus, A.D. De Lorenzo, P. Deurenberg, M. Elia, J.M. Gomez, B.L. Heitmann, L. Kent-Smith, J.C. Melchior, M. Pirlich, H. Scharfetter, A. Schols, C. Pichard, Bioelectrical 
impedance analysis - part 1: review of principles and methods. Clinical Nutrition, 23 (2004) 12261243.

[33] W.J. Hannan, S.J. Cowen, K.C.H. Fearson, C.E. Plester, J.S. Falconer, R.A. Richardson, Evaluation of multi-frequency bioimpedance analysis for the assessment of extracellular and total body water in surgical patients. Clinical Science, 86 (1994) 479-485.

[34] F. Clemente, P. Arpaia, C. Manna, Characterization of human skin impedance after electrical treatment for transdermal drug delivery. Measurement, 46 (2013) 3494-3501.

[35] F. Clemente, M. Romano, P. Bifulco, M. Cesarelli, EIS measurements for characterization of muscular tissue by means of equivalent electrical parameters. Measurement, 58 (2014) 476-482.

[36] M. Rehman, A.J.A. Abu Izneid, M.Z. Abdullah, M.R. Arshad, Assessment of quality of fruits using impedance spectroscopy. International Journal of Food Science \& Technology, 46 (2011) 1303-1309.

[37] L. Ragni, E. Iaccheri, C. Cevoli, A. Berardinelli, A. Bendini, T. Gallina Toschi, A capacitive technique to assess water content in extra virgin olive oils. Journal of Food Engineering, 116 (2013) 246-252.

[38] F.J. Ferrero, M. Valledor, J.C. Campo, Screening method for early detection of mastitis in cows. Measurement, 47 (2014) 855-860.

[39] C.M. Bhatt, J. Nagaraju, Non-destructive method to estimate the moisture content in bread using multi-channel electrical impedance spectroscopy. IEEE Sensors Applications Symposium (SAS) 2009.

[40] M.H. Hussin, A.A. Rahim, M. Nasir, M. Ibrahim, N. Brosse, The capability of ultrafiltrated alkaline and organosolv oil palm (Elais guineensis) fronds lignin as green corrosion inhibitor for mild steel in 0.5 M HCl solution. Measurement, 78 (2016) 90-103.

[41] L.Y.S. Helen, A.A. Rahim, B. Saad, M.I. Saleh, P. Bothi Raja, Aquilaria Crassna leaves extracts - a green corrosion inhibitor for mild steel in $1 \mathrm{M} \mathrm{HCl}$ medium. International Journal of Electrochemical Science, 9 (2014) 830-846. 
[42] P.M. Dasami, K. Parameswari, S. Chitra, Corrosion inhibition of mild steel in 1MH2SO4 by thiadiazole Schiff bases. Measurement, 69 (2015) 195-201.

[43] K.R. Ansari, M.A. Quraishi, A. Singh, Pyridine derivatives as corrosion inhibitors for N80 steel in 15\% $\mathrm{HCl}$ : Electrochemical, surface and quantum chemical studies. Measurement, 76 (2015) 136-147.

[44] P. Zoltowski, On the electrical capacitance of interfaces exhibiting constant phase element behaviour. Journal of Electroanalytical Chemistry, 443 (1), (1998), 149-154.

[45] S. Ashour, M. Khateeb, Conductometric titration method for determination of Alfuzosin Hydrochloride and Fexofenadine Hydrochloride using Sodium Tetraphenylborate. Canadian Chemical Transactions, 1, 4 , (2013), 292-304.

[46] G. Franchini, C. Preti, L. Tassi, G. Tosi, Effects of temperature and solvent composition on conductometric titrations in nonaqueous mixed solvents. Analytical Chemistry, 60, (1988), 23582364.

[47] M. Grossi, M. Lanzoni, A. Pompei, R. Lazzarini, D. Matteuzzi, B. Riccò, Detection of microbial concentration in ice-cream using the impedance technique. Biosensors \& Bioelectronics, 23, (2008) 1616-1623.

[48] M. McRoberts, Beginning Arduino, second ed., Apress, New York, 2013. 


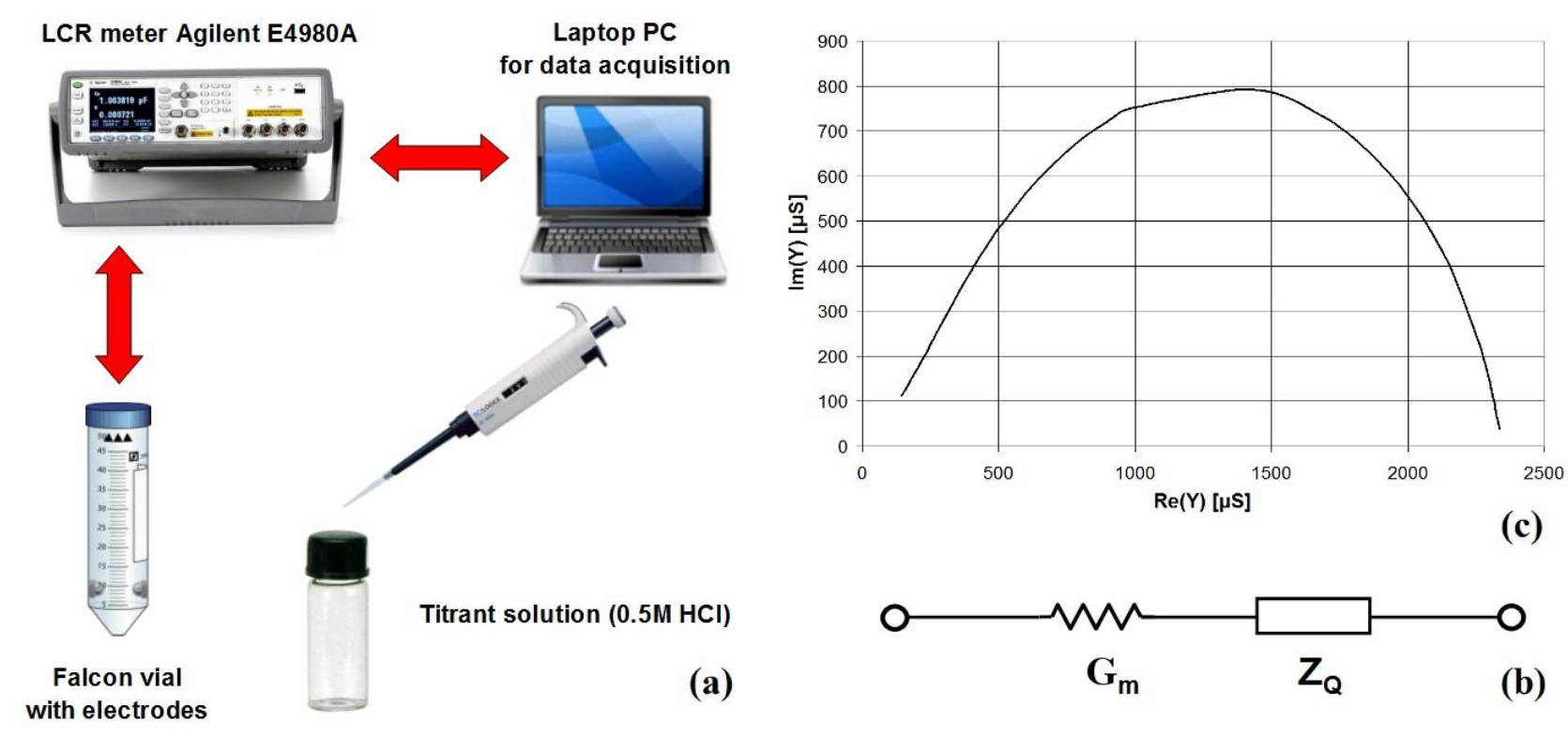

Fig. 1. (a) Bench-top experimental setup used to test the feasibility of the proposed technique, (b) electrical model of the system (essentially a couple of stainless steel electrodes in direct contact with the sample under test), (c) Nyquist plot for a MWF sample with $\mathrm{C}_{\mathrm{oil}}=4.46 \%$. 

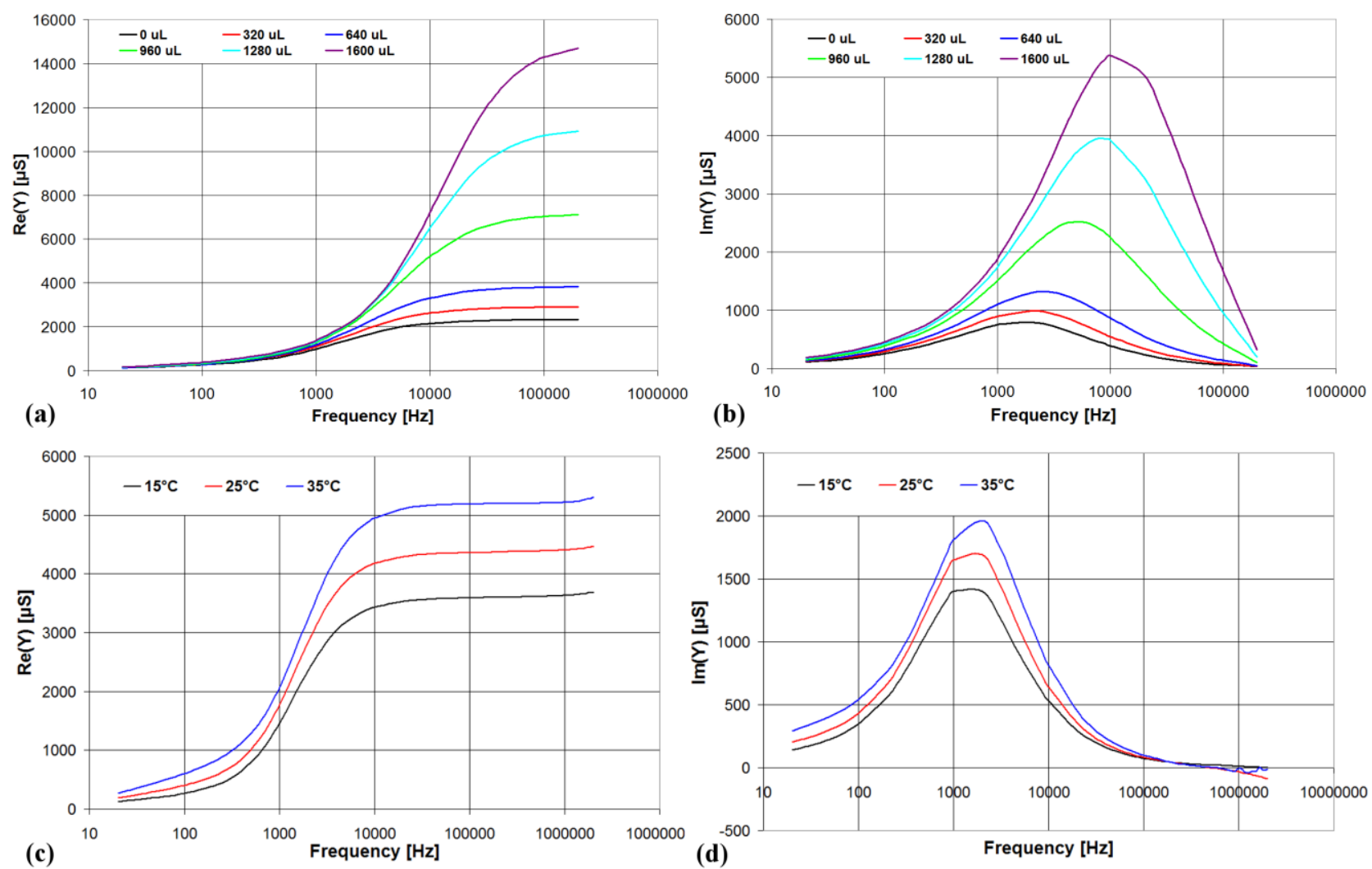

Fig. 2. Bode plots, (a) $\operatorname{Re}(\mathrm{Y})$ and (b) $\operatorname{Im}(\mathrm{Y})$ as function of frequency, for a MWF sample with $\mathrm{C}_{\mathrm{oil}}$ $=4.46 \%$ before and after titration with different volumes of titrant $(0.5 \mathrm{M} \mathrm{HCl})$. Bode plots, $(\mathrm{c})$ $\operatorname{Re}(\mathrm{Y})$ and (d) $\operatorname{Im}(\mathrm{Y})$ as function of frequency, for a MWF sample with $\mathrm{C}_{\mathrm{oil}}=6 \%$ for three different temperatures: $15^{\circ} \mathrm{C}, 25^{\circ} \mathrm{C}$ and $35^{\circ} \mathrm{C}$. 

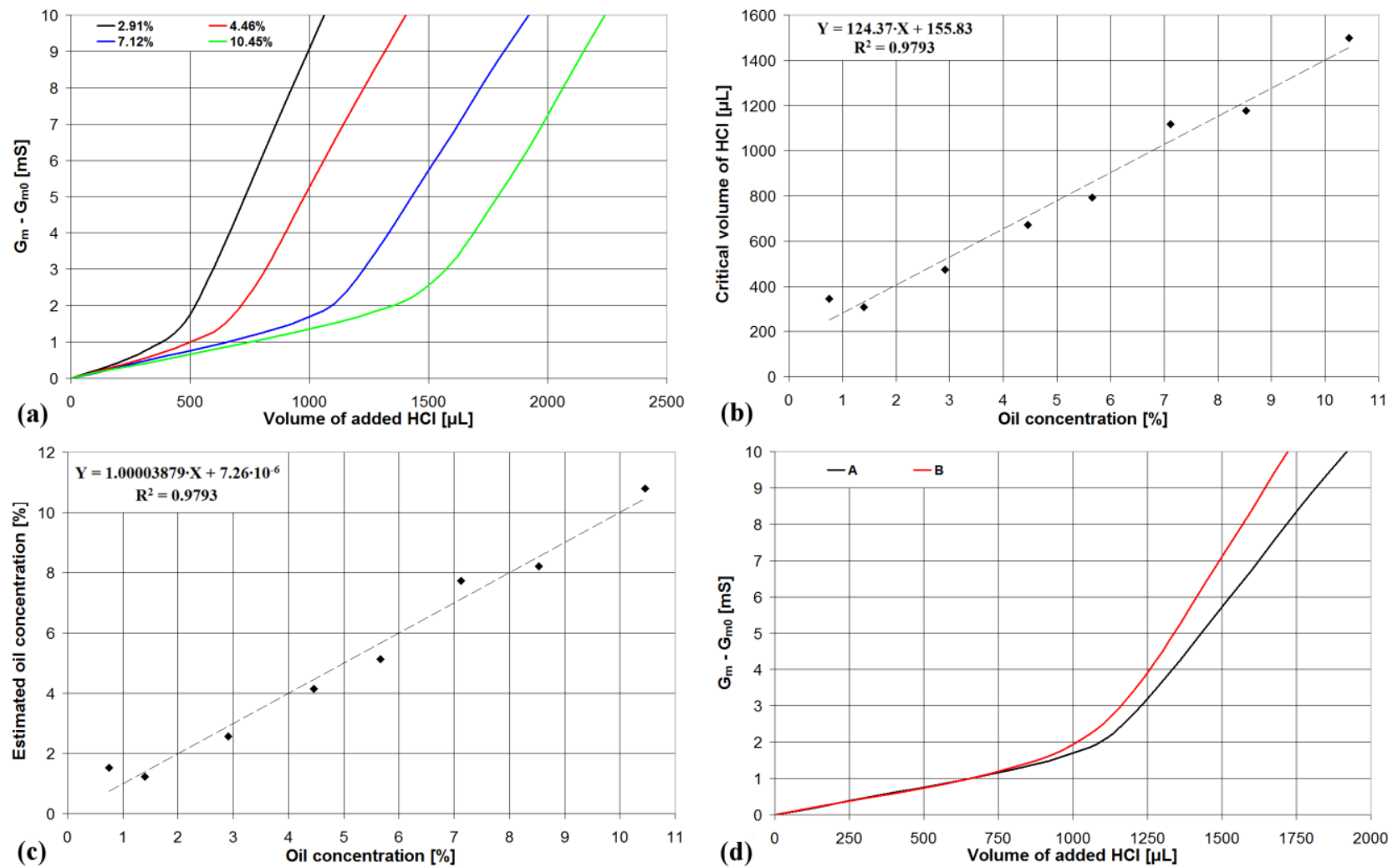

Fig. 3. (a) Electrical conductance variation vs. volume of added titrant for MWF samples with different $\mathrm{C}_{\text {oil }}$ values ; (b) scatter plot of critical volume of titrant vs. $\mathrm{C}_{\text {oil }}$ for the whole set of MWF tested samples; (c) scatter plot of estimated vs real $\mathrm{C}_{\mathrm{oil}}$ for the whole set of tested MWF samples; (d) electrical conductance variation vs volume of added titrant for two repeated assays on a sample with $\mathrm{C}_{\mathrm{oil}}=7.12 \%$. 

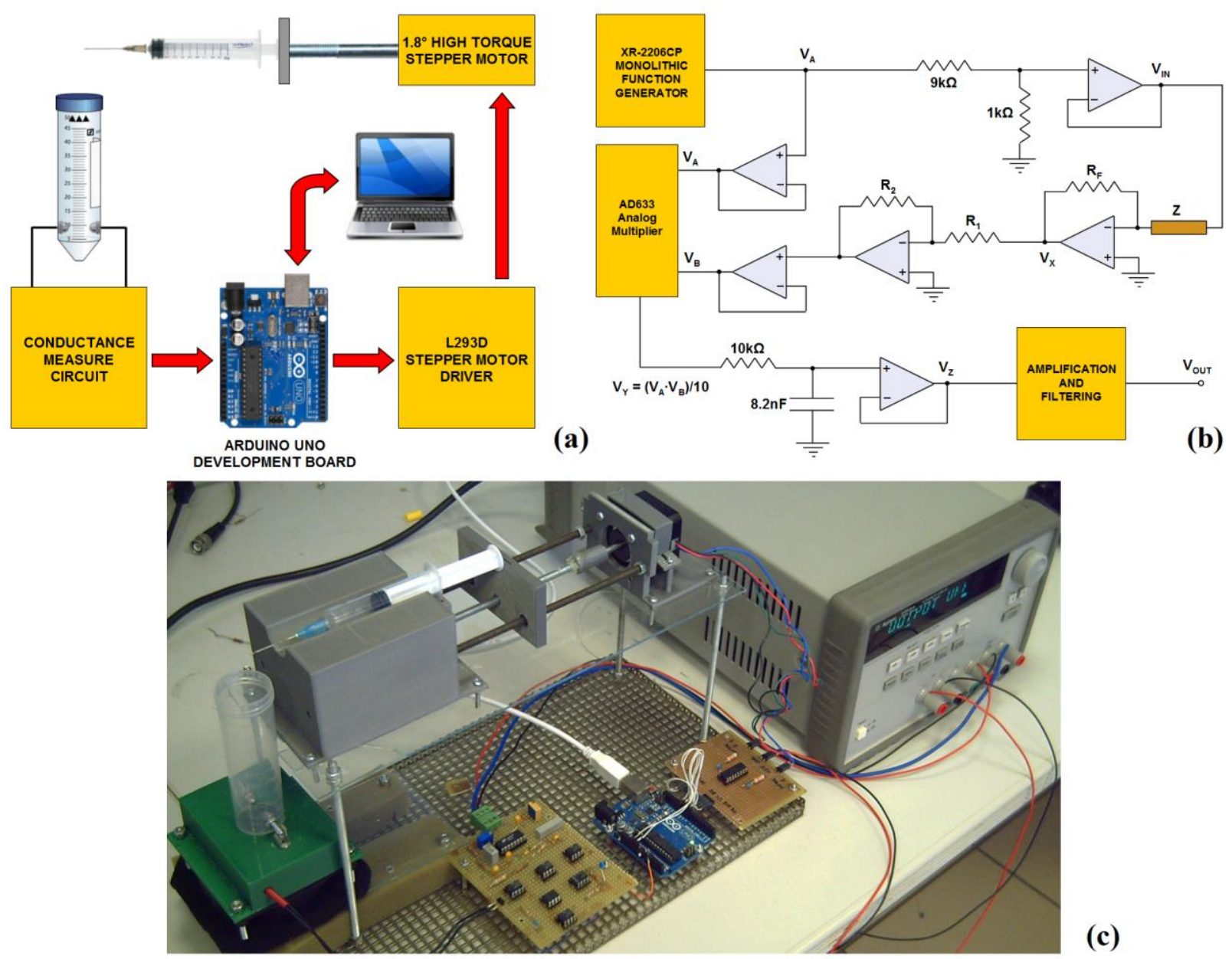

(c)

Fig. 4. (a) Schematics of the automatic electro-mechanical system to measure the oil concentration in MWF samples, (b) electronic board designed to measure the sample electrical conductance, (c) picture of the system. 

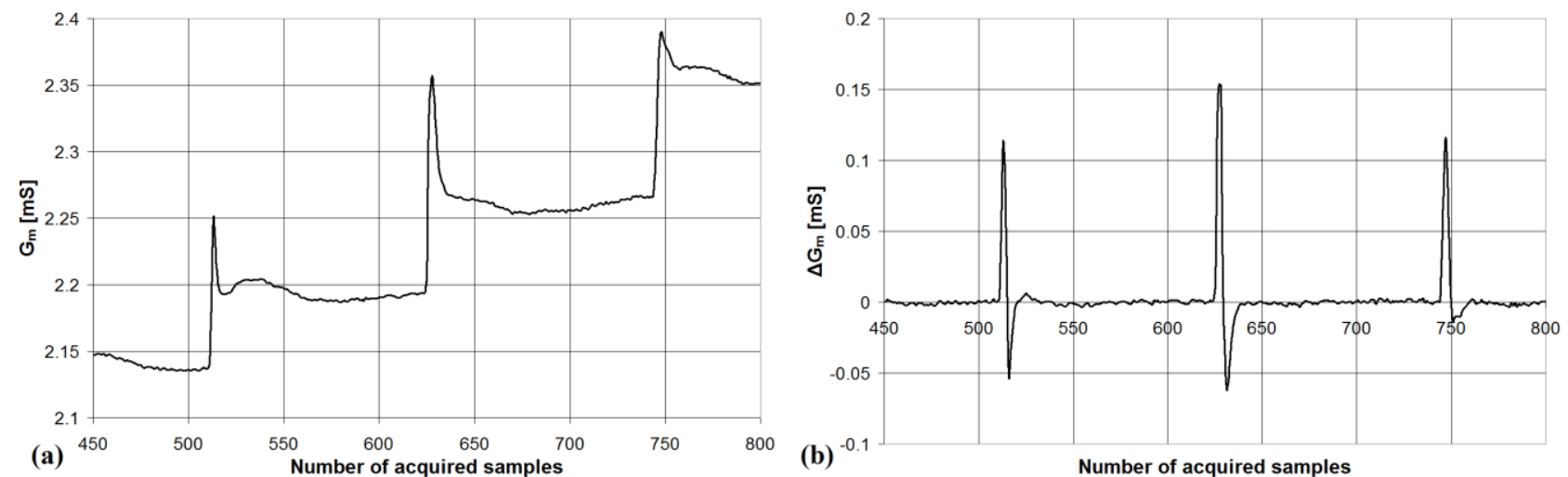

Fig. 5. (a) Electrical conductance $\mathrm{G}_{\mathrm{m}}$ and (b) variation of electrical conductance $\Delta \mathrm{G}_{\mathrm{m}}$ as function of the number of acquired samples (a $\mathrm{G}_{\mathrm{m}}$ sample is acquired every $250 \mathrm{~ms}$ ). A steep increase of $\mathrm{G}_{\mathrm{m}}$ and $\Delta \mathrm{G}_{\mathrm{m}}$ corresponds to the inoculation of a titrant drop in the sample. 

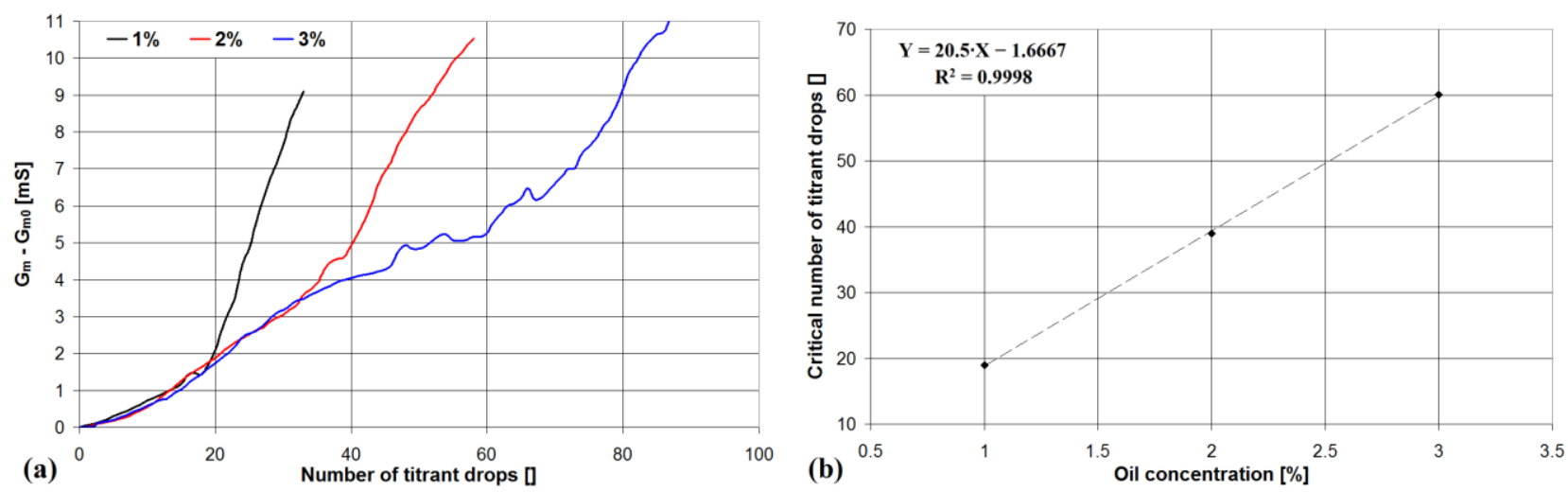

Fig. 6. (a) Variation in the measured conductance as function of the number of titrant drops for MWF samples with different values of $\mathrm{C}_{\mathrm{oil}}$ and (b) corresponding scatter plot. 